\title{
GESTÃO DE ENERGIA E A ISO 50001: AÇÕES ENTRE DUAS ORGANIZAÇÕES DE SETORES DIFERENCIADOS
}

\section{ENERGY MANAGEMENT AND THE ISO 50001: ACTIONS BETWEEN TWO ORGANIZATIONS OF DIFFERENTIATED SECTORS}

\author{
D. A. NUNES ${ }^{1}$, G. A. BARBOSA ${ }^{1}$, P. H. RATZINGER ${ }^{1}$, J. A. R. MORAES ${ }^{1}$ and A. L. E. SILVA ${ }^{1, *}$ \\ ${ }^{1}$ University of Santa Cruz do Sul, Department of Engineering, Santa Cruz do Sul, Rio Grande do Sul, Brazil
}

${ }^{*}$ Corresponding author. University of Santa Cruz do Sul, Department of Engineering, Santa Cruz, do Sul, Rio Grande do Sul, Brazil, Phone: +55 51 37177382 e-mail addressl: andresilva@unisc.br (A. L.E. Silva).

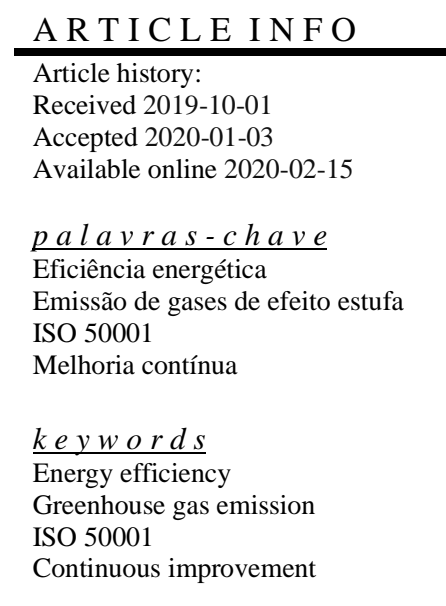

\begin{abstract}
A B S T R A C T
The aim of this paper is to analyze the main difficulties in the implementation of ISO 50001, addressing the advantages and possible disadvantages of adhering the standard and also encouraging non-certified companies to update themselves on the subject. As a data collection instrument, two different questionnaires were applied to two organizations located in the central region of Rio Grande do Sul state, Brazil. As for the results presented, it is emphasized that large industries are more concerned and engaged in reconciling profitability with environmental preservation through constant search for improvements in accordance with NBR's. But smaller companies, which have a harder time investing, are searching for ways to practice conscious consumption with basic method applications.
\end{abstract}

R E S UM O

O objetivo deste artigo é analisar as principais dificuldades na implementação da ISO 50001 , abordando as vantagens e as possíveis desvantagens de aderir à norma e também incentivar às empresas que não possuem a certificação se atualizar sobre o assunto. Como instrumento de coleta de dados aplicou-se dois questionários distintos em duas organizações localizadas na região central do estado do Rio Grande do Sul, Brasil. Quanto aos resultados apresentados destaca-se que as indústrias de grande porte estão mais preocupadas e engajadas em conciliar a lucratividade com a preservação do meio ambiente através de buscas constantes em melhorias de acordo com as NBR's. Porém, empresas de porte menor, as quais possuem uma maior dificuldade em relação a aplicação de investimento, estão em busca de maneiras de praticar o consumo consciente com aplicações de métodos básicos. 


\section{INTRODUCTION}

Durante anos, principalmente a partir da Revolução Industrial, a visão de uma boa qualidade de vida era diretamente relacionada à obtenção de lucros. Através do crescimento econômico, o processo de industrialização aumentou e com ele a utilização de recursos naturais, onde se refletiu uma degradação ambiental contínua.

Consequentemente, como resultado de uma má gestão dos recursos naturais da Terra, a população está sendo afetada diretamente com os quadros de poluição do ar, da água, do solo e o crescente número de desastres ambientais. Com isso, indivíduos e organizações começaram a repensar suas formas de atuar e como conduzir seus processos produtivos, com o objetivo de remediar e evitar maiores danos ao planeta.

Pensando nisso, a ABNT elaborou a ISO 50001, uma norma sobre Gestão de Energia, a qual possui o propósito de gerar um impacto positivo nas mudanças climáticas através da melhoria contínua do desempenho energético das organizações. Além dessa norma se integrar com os outros sistemas de gestão, a mesma tem a finalidade de melhorar a competitividade das empresas (FOSSA e SGARBI, 2018).

Assim, o presente trabalho aborda as vantagens e as possíveis desvantagens de aderir a esta norma, como também os motivos pelos quais as organizações estão implementando a mesma, através de relatos de outros autores. De forma geral, o estudo tem como objetivo analisar as principais dificuldades na implementação da ISO 50001 e quais ações estão sendo aplicadas em uma indústria processadora de tabaco, localizada no município de Santa Cruz do Sul - RS, a qual abastece uma importante fatia do mercado nacional e internacional. Possui uma infraestrutura composta por uma planta de processamento de tabaco e uma fábrica de cigarros, com um sistema operacional completo de tabaco em um único local.

E também relatar gastos, principalmente relacionados ao processo produtivo, de uma empresa que não possui sua gestão energética de acordo a ISO 50001, localizada no município de Candelária - RS. Está é uma filial de um grupo de móveis, atuando na parte Sul do país, como também com os países que limitam sua fronteira, possibilitando fácil logística de distribuição.

Procurou-se relatar melhorias reportadas por organizações que possuem a certificação da norma abordada (ISO 50001) e assim incentivar empresas que ainda não possuem a agregar conhecimento sobre gestão energética e assim pensar em uma futura implementação.

\section{REFERENCIAL TEÓRICO}

\subsection{Gestão Energética}

No decorrer dos anos, indivíduos e organizações vêm utilizando os recursos naturais de forma incorreta, e em uma época que a energia está diretamente relacionada às demandas da sociedade em relação ao conforto, necessita-se criar e praticar ações pensando em ajudar e remediar problemas ambientais emergentes. Estamos em um cenário onde a maior fatia da população vive na área urbana, e com previsões para até 2050 esta porcentagem representar aproximadamente $66 \%$, afetando proporcionalmente a concentração de consumo (COLLAÇO, 2017).

O desperdício de energia e o aumento das emissões de gases de efeito estufa decorrentes da utilização ineficiente de energia pelas organizações tornaram-se uma preocupação global (SOUZA et al., 2019). O setor industrial é responsável por grande parte do desse consumo, e já se percebe a necessidade e a importância de obter maior eficiência, buscando um melhor desempenho na produção com a redução e otimização do consumo de energia nos processos produtivos, a fim de garantir a competitividade industrial (SVENSSON \& PARAMONOVA, 2017).

Posto isto, o gerenciamento de energia foi identificado como uma solução que visa superar as dificuldades e melhorar a eficiência energética, trazendo benefícios econômicos e ambientais com a redução do consumo de energia dentro da organização sem afetar a qualidade e a produtividade (MCKANE et al., 2017). Desta forma, as melhorias na eficiência energética podem ser alcançadas com as práticas de gerenciamento, tanto por meio de ações repetitivas ou mesmo por ações únicas, como a compra de um motor mais eficiente (SVENSSON \& PARAMONOVA, 2017).

A ISO 50001 estabelece diretrizes para a implementação, manutenção e avaliação dos sistemas de gerenciamento de energia, visando tornar mais eficiente o uso de energia, melhorando a gestão energética, gerando benefícios para a organização. A implementação da ISO 50001 destina-se a redução nas emissões de gases de efeito estufa e outros impactos ambientais relacionados à energia (SOUZA et al., 2019).

De acordo com Aragão Neto (2005) citado por Batista e Flauzino (2012), possuir um sistema de gestão de energia aponta a existência de uma administração racional, o que por sua vez, dá visibilidade para conquistar novos investidores e repassa uma imagem positiva aos olhos da sociedade. Apesar dos benefícios previstos, muitas organizações brasileiras ainda não possuem a certificação da norma, que possui o perfil de salientar a melhoria contínua no sistema de gestão de energia e conciliar a melhoria no desempenho energético de uma empresa. Com isso, a maior dificuldade da empresa se torna a identificar as barreiras geradas na esfera organizacional e eliminá-las para assim poder implementar a ISO 50001 (ASSUNÇÃO e MOROZ, 2016).

\subsection{Passos para a aplicação da ISO 50001}

Para a execução do passo 1 , se necessita analisar o contexto da organização, conhecer as necessidades e as características gerais que envolvem a demanda de energia. Sendo assim, é uma fase de observação, onde deverá ser avaliado os principais elementos para a estruturação e execução do Sistema de Gestão de Energia (SGEn).

Após, no passo 2 é onde será planejado e estabelecido os objetivos e metas energéticas (PLAN), sendo um dos passos mais importantes do processo. Neste momento a organização 
detalha o uso específico da energia utilizada juntamente com seus processos internos, sendo possível definir as melhorias para o processo analisado.

A seguir, no passo 3, é gerenciado o uso e consumo de energia (DO), o qual serão abordadas as questões operacionais da energia, que primeiramente necessita suportar a operação do SGEn. Após garantir seu bom funcionamento, realiza-se o detalhamento dos aspectos específicos de controle operacional e também se especifica os procedimentos.

Já no passo 4 realiza-se o monitoramento do desempenho e melhorias (CHECK), onde é verificado na prática as melhorias projetadas, através do auxílio de processos de monitoramento. Essa é uma fase de extrema importância para a efetivação do Sistema de Gestão de Energia (SGEn).

E por fim o passo 5, que é a fase de tomada de decisões onde realiza-se a busca por melhorias contínuas (ACT), pois o SGEn necessita estar em constante mutação, para assim estar sempre alinhado com as condições atuais. Também se faz necessário realizar constantemente auto avaliações para identificar as possíveis não conformidades e as devidas ações corretivas. A Figura 1 representa a estrutura geral da ISO 50001 e cada um dos seus ramos.

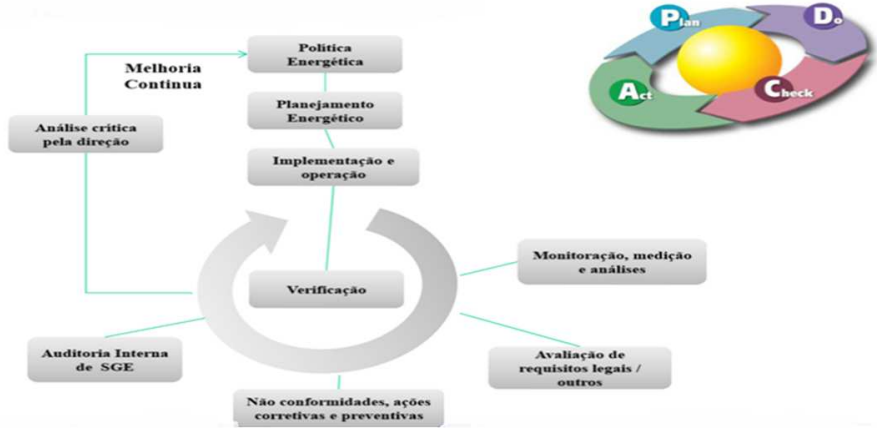

Figure 1 - Estrutura Geral da ISO 50001.

\subsection{Relatos de organizações com certificação da ISO 50001}

Caso WEG - Atualmente muitas organizações de diferentes setores já possuem sua gestão de energia de acordo com a ISO 50001, porém a primeira indústria do setor eletroeletrônico brasileiro a receber a certificação desta norma foi a WEG, unidade localizada em Jaguará do Sul - SC. A mesma é responsável pela produção de motores elétricos trifásicos o que resultava em um grande consumo de energia, com isso, desde o início se pensou em uma abordagem estruturada e permanente para a organização.

Com a elaboração do planejamento energético, a organização detectou através do estudo do uso significativo de energia, que equipamentos e processos representavam $80 \%$ do consumo de energia da unidade. A partir dos dados obtidos, foi o momento que a empresa estabeleceu suas metas e objetivos, onde pretendia reduzir o consumo de energia com a diminuição de $10 \%$ no $\mathrm{kWh} / \mathrm{cv}$ produzido e $11 \%$ no tempo de ensaio. A Figura 2 ilustra os resultados obtidos pela indústria após a implementação da norma.

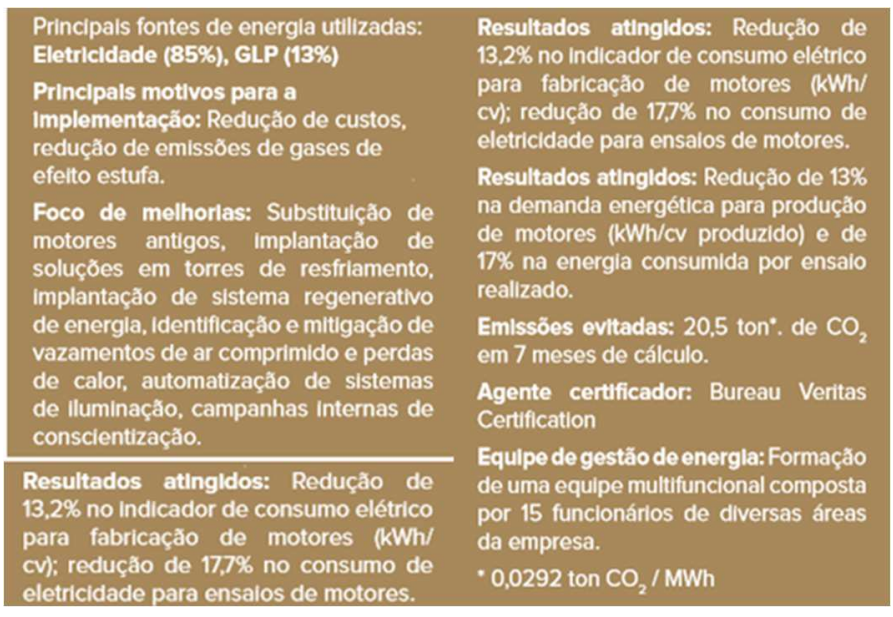

Figure 2 - Resultados obtidos com a implementação da ISO 50001.

Caso GM - A indústria do setor automotivo General Motors (GM) antes de 2016 já possuía 4 unidades com a certificação da ISO 50001 e em 2016 começou a realizar a implementação na indústria situada em São Caetano do Sul RS. As organizações da GM possuem um monitoramento denominada GM2100, onde permite a avaliação a respeito dos indicadores de consumo e mapeia comportamentos estranhos, também está integrado um mapa que relata as principais áreas consumidoras.

Com este sistema foi possível identificar as principais formas de energia utilizada em cada unidade certificada, sendo assim, servindo como base para possíveis oportunidades de melhorias na empresa. A partir disso, a organização determinou seu objetivo como reduzir $20 \%$ (com base nos valores de 2010) no consumo de energia/veículo produzido com redução até 2020. Após implementação da norma, a indústria obteve resultados conforme apresenta Figura 3.
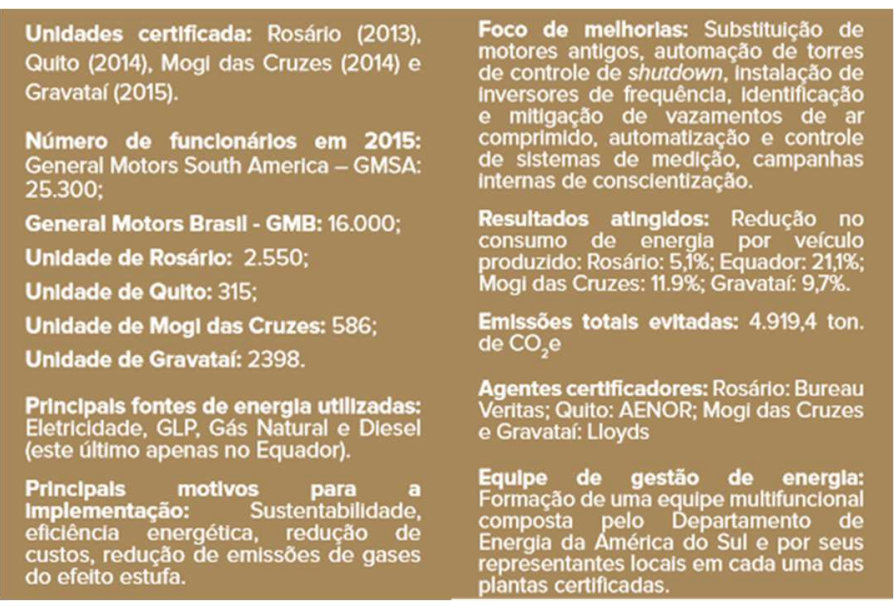

Figure 3 - Resultados obtidos na unidade de São Caetano do Sul. 


\section{METODOLOGIA}

A pesquisa classifica-se como descritiva e exploratória, pois o nível de profundidade abordada no estudo buscou maior conhecimento para desenvolver e esclarecer ideias, atuando juntamente com a observação de dados, sem possuir qualquer interferência do pesquisador (GIL, 2017). Prevê ainda relatar vantagens e desvantagens de organizações que aplicam a ISO 50001, como também incentivar e estimular as empresas que não possuem a se atualizar a respeito do assunto e talvez futuramente fazer a implementação da mesma.

A metodologia utilizada fundamenta-se no método dedutivo, pois acredita-se que as empresas que possuem uma gestão de energia de acordo com a norma abordada no decorrer do trabalho obtiveram resultados positivos. E como método de procedimento, baseou-se em análises qualitativas e quantitativas.

No intuito de agregar um conhecimento confiável além da realização de pesquisas bibliográficas, com relatos de aplicações existentes, optou-se na criação de dois questionários fechados e diferentes. Um voltado para a organização que não possui a gestão de energia, com propósito de levar conhecimento e fatos das melhorias de possuir esta gestão. E o outro com foco em empresas com aplicabilidade dessa gestão de acordo com a norma, baseado em captar e comprovar a sua eficácia (APÊNDICE 1).

Para a coleta de dados, criou-se questionários apenas com questões objetivas, facilitando a compreensão e a realização de resultados concretos. Com isso, para a efetivação da metodologia, realizou-se buscas por empresas do Rio Grande do Sul, uma que possui sua gestão de energia, mesmo não estando completamente adequada à ISO 50001 e outra que não possui nenhuma gestão de energia. Por fim selecionou as indústrias do segmento moveleiro e do tabaco.

\section{RESULTADOS}

Em consideração ao foco do estudo, que é sobre o consumo excessivo de energia elétrica gerado nos processos de fabricação, e o quanto o uso irracional é prejudicial ao meio ambiente e ao mesmo tempo, aos custos financeiros; A empresa do setor de móveis, com o intuito de se manter competitiva no mercado, teve que realizar mudanças em seu layout e por conta disso, alguns motores que possuem alta rotação e consumo de energia, tiveram que sofrer algumas modificações nas suas instalações. No ano de 2014 executou-se a instalação de um banco de capacitores sobre os mesmos, prevendo-se a redução do consumo de energia na empresa investigada.

Esse sistema, teve o intuito de armazenar energia e deixar o fluxo mais leve, pois quando as máquinas eram ligadas manualmente as mesmas elevavam o consumo de energia para bandeira vermelha, como também, o aumento de perdas no processo, pois sem o banco de capacitores, não se encontrava o armazenamento de energias. Portanto, fica evidente que, a utilização desse método beneficiou a empresa de forma significativa, somando valores satisfatórios e diminuindo o consumo relativamente em torno de $16 \%$. Conforme dados representados na Tabela 1 .
Table 1 - Cálculo de consumo energético em KW, entre 2014 à 2018.

\begin{tabular}{cc|}
\hline Ano & Consumo \\
\hline $\mathbf{2 0 1 4}$ & 775736 \\
$\mathbf{2 0 1 5}$ & 671558 \\
$\mathbf{2 0 1 6}$ & 612440 \\
$\mathbf{2 0 1 7}$ & 668549 \\
$\mathbf{2 0 1 8}$ & 651747 \\
\hline
\end{tabular}

Fonte: Adaptado de Mays apud Greenhalg (1997).

Após coleta de informações referentes aos anos de 2014 à 2018, identificou-se que a média mensal que a empresa gasta é de $54.312,25 \mathrm{~kW}$ sendo que $23 \%$ do valor é referente aos meses de uso dos ar condicionados, cerca de $16.286,4 \mathrm{~kW}$ no setor da química, onde uma substância chamada de TDI, necessita estar na temperatura entre $14^{\circ} \mathrm{C}$ à $16^{\circ} \mathrm{C}$ nos tanques de conservação para ter rendimento em seu eventual processo. No restante do ano, eleva-se o índice do consumo chegando em $35 \%$, utilizando-se quase o dobro de energia com as lâmpadas que efetuam o aquecimento, chegando-se a $28.800 \mathrm{~kW}$.

Ao fazer um eventual comparativo entre os dois aquecedores citados anteriormente, foi realizado uma previsão de como seria a diferença durante seis meses se houvesse a substituição de todas as 160 lâmpadas, por quatro novos ares condicionados de 60.000 Btus. Primeiramente, teria os custos de montagem e aquisição dos aparelhos, portanto, somente no terceiro mês se obteriam os lucros e ao chegar no último mês do ano, observa-se que as lâmpadas somariam R \$ 120.960,00 e os ares condicionados novos com $\mathrm{R} \$ 98.402,88$. Uma diferença bastante significativa, totalizando $18,64 \%$ na redução do consumo energético, como também para os seus valores mensais com $\mathrm{R} \$ 22.557,12$ de resultados de economia durante seis meses, caso a mudança seja efetuada.

Com a aplicação do questionário na indústria processadora de tabaco, obteve-se que a empresa está classificada como de grande porte, possuindo mais de 500 funcionários, onde a mesma relata possuir comprometimento e procura constantemente maneiras para evitar agredir o meio ambiente. Porém com informações repassadas pela coordenadora do meio ambiente, atualmente a organização não possui a certificação da ISO 50001, mas já está em fase de implementação da gestão de energia de acordo com a norma, consequentemente, não sendo possível adquirir dados de melhorias.

Entretanto, foi possível obter algumas práticas que estão sendo aplicadas como: monitoramento de gastos de energia e reutilização da água, desenvolvimento constante de campanhas internas e externas sobre consumo consciente, máquinas em stand-by desligadas, implementação de lâmpadas de led e ferramentas de produção com baixo consumo e de alta eficiência. Também, a mesma relatou que a maior dificuldade nesta fase de implementação está sendo transformar o planejamento em ação, pois é nesta parte que a colaboração e o engajamento de todos é de extrema importância para a eficácia do processo.

Como resultado do questionário aplicado a indústria de móveis obteve-se os seguintes gráficos que estão representados pelas Figuras 4, 5 e 6. 


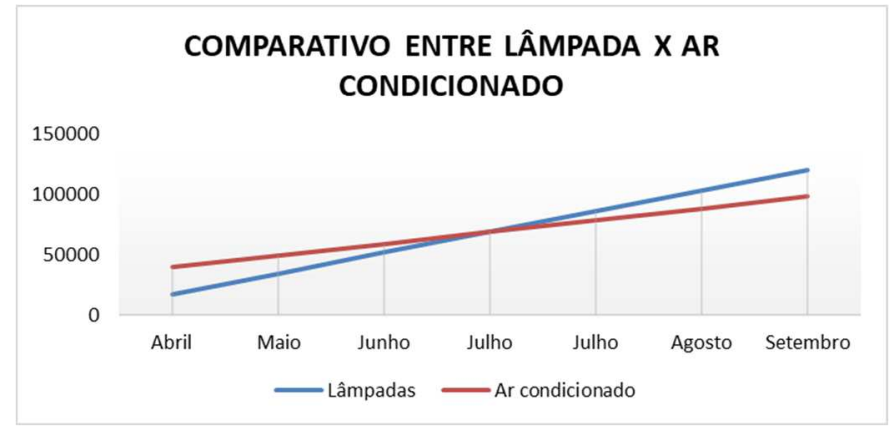

Figure 4 - Comparativo entre consumo de lâmpadas $x$ ar condicionado.

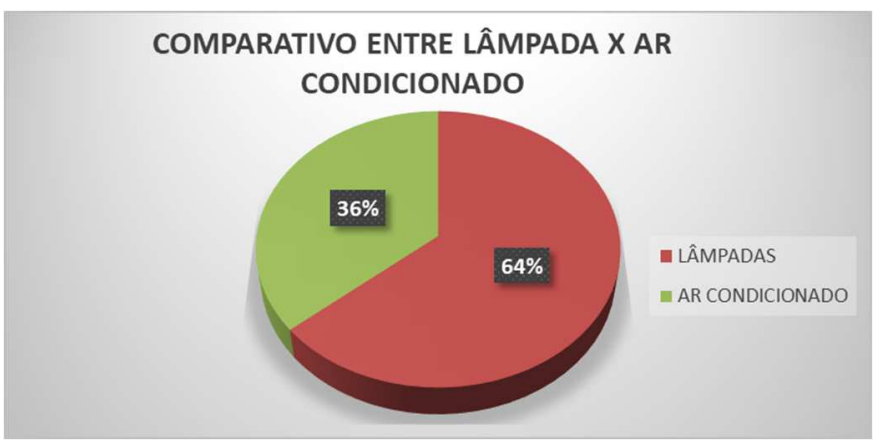

Figure 5 - Comparativo entre consumo no uso de ar condicionado x lâmpadas.

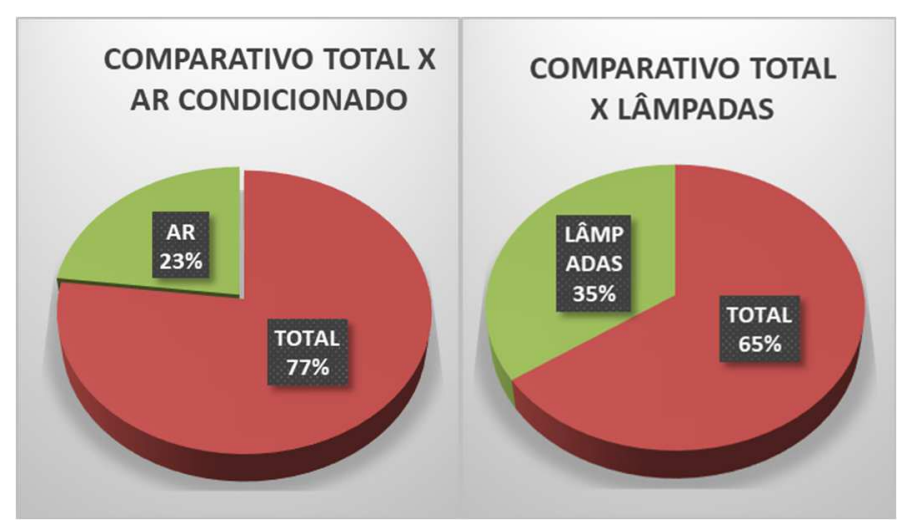

Figure 6 - Comparativo entre a representação do consumo atual das lâmpadas no setor de química $x$ consumo caso seja feito a mudança para ar condicionado.

\section{CONSIDERAÇÕES FINAIS}

Através das informações fornecidas pela indústria processadora de tabaco, a mesma busca e incentiva projetos de melhorias, principalmente as quais contribuam para a otimização do processo produtivo, sendo totalmente receptivas a ideias de seus colaboradores. A mesma procura manter o engajamento de seus funcionários e setores, visto que o destaque das operações da organização se dá através do trabalho integrado das divisões da companhia.

Assim, fica claro a preocupação da empresa em possuir e manter um ambiente agradável, tanto interno como externo, pensando no bem-estar da sociedade. A mesma reconhece que essa sinergia reflete em uma melhor eficiência em seus processos e rentabilidade dos negócios quando se concilia atitudes positivas referentes ao meio ambiente.

Se por um lado encontra-se uma indústria que está implementando a ISO 50001, pelo outro, possui uma que no momento por questões de custos e burocracias da sua matriz, ainda não se vê disposta para enfrentar essa realidade. Entretanto, para poder se manter em nível nacional, a indústria de móveis utiliza uma gestão energética bastante eficiente, sempre buscando melhorias contínuas, otimização em seus processos, e a preservação do meio ambiente como um foco, para continuar sendo uma empresa sustentável.

Desse modo, nota-se que as mudanças feitas nos últimos anos sobre o banco de capacitores beneficiaram a empresa somando valores satisfatórios e diminuindo o consumo relativamente em torno de $16 \%$. Visto que, antes da implantação o consumo era de $775.736 \mathrm{KW}$ e no ano de 2018 , teve uma redução para 651.747 KW em consideração da mudança realizada.

Portanto, fica evidente que, mesmo a empresa aderindo ou não a ISO 50001, a importância com o meio ambiente e a utilização dos recursos naturais de forma racional, está sempre em pauta. Uma empresa que busca valorização no mercado e ter seu nome reconhecido, além de possuir produtos diferenciados, precisa ser sustentável.

\section{R E FER E N C I A S}

ASSUNÇÃO, L. A.; MOROZ, R. C. Estudo sobre sistema de gestão de energia em indústrias. 2016. 38f. Trabalho de Conclusão Curso (Bacharelado em Engenharia Eletrônica) - Universidade Tecnológica Federal do Paraná. Ponta Grossa, 2016.

BATISTA, O. E.; FLAUZINO, R. A. Medidas de Gestão Energética de baixo custo como estratégia para redução de custos com energia elétrica. GEPROS. Gestão da Produção, Operações e Sistemas, v. 7, n. 4, p. 117-134, Out./Dez. 2012.

COLLAÇO, A. M. F. Perspectiva da Gestão de Energia em âmbito municipal no Brasil. Instituto de Estudos Avançados, São Paulo, n. 89, p. 213-235, 2017.

FOSSA, J. A.; SGARBI, A. F. Guia para Aplicação da Norma ABNT NBR ISO 50001 Gestão de Energia. 1 ed. São Paulo: International Copper Association Brazil, 2018.

GIL, A. Como elaborar projetos de pesquisa. São Paulo: Atlas, 2017.

MCKANE, A. et al. Predicting the quantifiable impacts of ISO 50001 on climate change mitigation. Energy Policy, v. 107, p. 278-288, 2017.

SOUZA, J. M. et al. Which factors does the diffusion of ISO 50001 in different regions of the world is influenced? Journal of Cleaner Production, v. 226, p. 759-767, 2019.

SVENSSON, A.; PARAMONOVA, S. An analytical model for identifying and addressing energy efficiency improvement opportunities in industrial production systems - Model development and testing experiences 
from Sweden. Journal of Cleaner Production, v. 142 p. 2407-2422, 2017.

\section{APÊNDICE}

Questionário sobre gestão de energia para realização na empresa processadora d tabaco, a qual está implementando a gestão de energia de acordo com a ISO 50.001

1. Em qual classificação a empresa se enquadra:

( ) Microempreendedor Individual - MEI ( ) Microempresa - ME (até 19 empregados)

( ) Pequena (20 a 99 empregados) ( ) Média (100 a 499 empregados)

( ) Grande Empresa (mais de 500 empregados)

2. A empresa procura e preocupa-se em minimizar seus impactos ambientais?

( ) $\operatorname{Sim}($ ) Não

3. A organização possui a implementação de Sistemas de Gestão de Energia de acordo com a ISO 50001? ( ) Sim ( ) Não ( ) Em fase de implementação

4. Se sim, você considera que houve melhorias após a implementação?

( ) Sim ( ) Não ( ) Está em fase de implementação

5. A organização possui a implementação de Sistemas de Gestão de Energia de acordo com a ISO 50001? ( ) Sim ( ) Não ( ) Em fase de implementação

6. Se sim, você considera que houve melhorias após a implementação?

( ) Sim ( ) Não ( ) Está em fase de implementação

7. A organização possui um monitoramento de gastos de energia e reutilização da água da chuva? ( ) Sim ( ) Não

8. A empresa desenvolve campanhas internas ou externas sobre o consumo consciente? ( ) Sim ( ) Não

9. Entre as energias presentes na natureza, quais a empresa utiliza?

( ) Energia hidrelétrica ( ) Energia solar ( ) Energia elétrica (gerador)

( ) Outras Quais?

10. A empresa possui práticas para diminuir o consumo de energia? Se sim, quais?

( ) Lâmpadas de LED ( ) Ferramentas de produção com baixo consumo

( ) Aplicativos de monitoramento do consumo de equipamentos em horários após expediente

( ) Máquinas em Stand By desligadas ( ) outras medidas Quais?

11. A organização busca e incentiva projetos que contribuam para a otimização dos processos produtivos? ( ) Sim ( ) Não

12. Em sua opinião, quais foram ou estão sendo, as maiores dificuldades para conquistar a certificação da ISO 50001 ?

( ) Complexidade envolvida na aplicação ( ) Transformar planejamento em ação

( ) Custos financeiros ( ) Falta de conhecimento ( ) Outros Quais?
Questionário sobre gestão de energia para realização na empresa de móveis, a qual não possui gestão de energia

1. Em qual classificação sua empresa se enquadra:

( ) Microempreendedor Individual - MEI ( ) Microempresa - ME (até 19 empregados)

( ) Pequena (20 a 99 empregados) ( ) Média (100 a 499 empregados)

( ) Grande Empresa (mais de 500 empregados)

2. A empresa procura e preocupa-se em minimizar seus impactos ambientais?

( ) $\operatorname{Sim}$ ( ) Não

3. Como você considera seu nível de conhecimento a respeito da ISO 50001 ?

( ) Ótimo ( ) Bom ( ) Regular ( ) Ruim ( ) Péssimo ( ) Não possuo conhecimento

4. Em sua opinião, qual o principal motivo para a organização não optar pela aplicabilidade dessa Gestão? ( ) Complexidade envolvida na aplicação ( ) Falta de conhecimento ( ) Custos financeiros ( ) Outros Quais?

5. Entre as energias presentes na natureza, quais a empresa utiliza?

( ) Energia hidrelétrica ( ) Energia solar ( ) Energia elétrica (gerador)

( ) Outras Quais?

6. O consumo de energia gasto pela indústria é:

( ) Muito alto ( ) Alto ( ) Razoável ( ) Baixo

7. Nos últimos anos, a empresa teve práticas para diminuir o consumo de energia? Se sim, quais?

( ) Lâmpadas de LED ( ) Ferramentas de produção com baixo consumo

( ) Aplicativos de monitoramento do consumo de equipamentos em horários após expediente

( ) Máquinas em Stand By desligadas ( ) Outras medidas Quais?

8. A empresa propõe medidas para reduzir a emissão de gases do efeito estufa?

( ) $\operatorname{Sim}($ ) Não

9. Você sabia que possuir uma gestão de energia a organização está contribuindo para reduzir a emissão de gases do efeito estufa? Pois reduzindo o consumo, consequentemente, se faz necessário uma quantia menor de produção de energia elétrica. ( ) $\operatorname{Sim}($ ) Não

10. Uma boa gestão de energia contribui na otimização dos processos produtivos, pois para que se torne possível utilizar a energia elétrica de forma consciente, se faz necessário mudar hábitos. Você concorda? ( ) Sim ( ) Não

11. Você considera que mostrar-se preocupado com o meio ambiente, com práticas sustentáveis e campanhas de conscientização, ajudam a valorizar a imagem da empresa perante a sociedade? ( ) $\operatorname{Sim}($ ) Não 